\title{
FAZER PRECARIZAR: neoliberalismo autoritário e necrogovernamentalidade
}

\author{
Fábio Luís Franco*
}

\begin{abstract}
Neste artigo, trata-se de explorar as articulações entre necropolítica e gestão neoliberal do trabalho no Brasil. Pretende-se sustentar que o neoliberalismo autoritário opera tanto coercitivamente, valendo-se dos aparatos de segurança e de justiça, quanto a partir da gestão do sofrimento psíquico e dos processos de subjetivação. Para tanto, parte-se da compreensão de que a necropolítica neoliberal envolve, também, intervenções visando a fazer precarizar, isto é, a produzir sofrimento nos corpos por meio da administração de condições mortíferas, tal como fica explicito com a plataformização neoliberal do trabalho no Brasil. Por fim, o artigo introduz algumas considerações sobre os impactos dessa gestão necropolítica neoliberal da precariedade nas formas de subjetivação dos trabalhadores, lançando luz sobre a necrogovernamentalidade neoliberal enquanto gestão das condições de emergência da angústia.

Palavras-chave: Necropolítica. Neoliberalismo. Plataformização. Trabalho. Angústia.
\end{abstract}

\section{NECROPOLÍTICA, NEOLIBERA- LISMO, AUTORITARISMO}

Em relação à biopolítica, a necropolítica é um conceito êxtimo, ao mesmo tempo interior e exterior, familiar e estranho, próximo e distante. Tal estatuto aparentemente paradoxal da necropolítica é derivado, em primeiro lugar, do fato de que esse conceito tornou inteligível um conjunto de dispositivos de poder-saber situados nas margens do sistema produtivo global, nas regiões submetidas ao colonialismo e ao imperialismo europeu e norte-americano, nas áreas de conflito no Oriente Médio, ao mesmo tempo que lançou luz sobre a multiplicação de enclaves mortíferos no interior dos países capitalistas avançados (Mbembe, 2003). Em segundo lugar, a extimidade da necropolítica expõe as cesuras, as contradições e os limites da alegada hegemonia das tecnologias biopolíticas desde o final do século XVIII, da qual partia Foucault ao afirmar que "O poder

* Universidade de São Paulo.

Av. Prof. Mello Moraes, 1721. Cep: 05508-030. Cidade Universitária. São Paulo - São Paulo - Brasil. fabio.sofia@gmail.com

https://orcid.org/0000-0001-7295-5015 já não conhece a morte. No sentido estrito, o poder deixa a morte de lado" (Foucault, 1997, p. 221, grifos nossos) para se ocupar preferencialmente da gestão da vida e da maximização da produtividade vital, tanto do indivíduo vivente quanto das populações.

Não que a biopolítica fizesse tabula rasa das presentificações da morte no governo dos vivos. "Como exercer o poder da morte, como exercer a função da morte, num sistema político centrado no biopoder?” (Ibidem, p. 227), perguntava Foucault sintetizando o que ele considerava ser uma "antinomia central da nossa razão política” (Foucault, 2001a, p.1634). A despeito das diferenças, pode-se dizer que a solução que lhe propuseram alguns dos principais representantes da tradição biopolítica (Cf. Foucault, 1997; Agamben, 2002; Esposito, 2004) consistiu em adotar o que os juristas designam como "critério hierárquico": dissolvia-se a antinomia atribuindo ao biopoder um estatuto hierarquicamente superior ao poder da morte, cuja existência e funcionamento passavam a ser considerados subordinados às exigências da razão biopolítica. Ao fim e ao cabo, restaurava-se a unidade do poder da vida ao 
mesmo tempo em que se conferia um lugar às práticas tanatopolíticas.

Mas, a tanatopolítica não é a necropolítica. Enquanto o primeiro termo, recorrente nos teóricos da biopolítica, refere-se à função política da morte que tem lugar no governo da vida e dos vivos, a necropolítica é o que não se subordina ao biopoder - ainda que possa se interseccionar com esse -, pois faz da morte do inimigo, da destruição do seu corpo, da produção do cadáver um "objetivo primário e absoluto” (Mbembe, 2003, p.12). Nesse caso, não é mera nota de rodapé filológica explicitar que Thanaton, em grego, é a morte em sua acepção mais abstrata, ao passo que Nekron é a morte que se faz carne, cadáver.

A necropolítica, portanto, é o poder da morte que se exerce sobre e por meio do corpo. Dos antigos rituais públicos de suplício no Ancien Régime aos genocídios da população preta, indígena, trans no Brasil contemporâneo, a necropolítica se conjuga como poder de fazer morrer, consequência da cada vez mais pulverizada e repartida decisão soberana sobre o estado de exceção e o abandono da vida nua (Cf. Mbembe 2003; Agamben, 2012). Mas, a necropolítica não se esgota nas formas passadas e presentes de exercício da soberania. Além dessas, há outras conjugações da necropolítica: fazer desaparecer, torturar, expor à morte, e, também, gerir o sofrimento dos corpos por meio da administração de condições mortífeసี ras, como ocorre nas chamadas guerras infraㄱ -estruturais em que os alvos são os sistemas de ปे abastecimento, de circulação e de saúde das ฮิ populações inimigas. No cerco israelense à fai10 $x a$ de Gaza, nas intervenções norte-americanas $\dot{2}$ no Iraque, na ocupação armada de territórios ஓं favelizados, a necropolítica se exerce em nome da nova palavra de ordem das guerras contemporâneas de contra-insurgência: bomb now, die later, de forma que

não é preciso matar as pessoas, basta provocar o colapso de suas condições de vida. E assim foi feito (e estou citando): a destruição sistemática da infra-estrutura (eletricidade, abastecimento, água, sane- amento etc) não caracterizaria bem um bombardeio cirúrgico, mas o que um médico norte-americano chamou de 'neurocirúrgico': com a precisão alardeada, as bombas inteligentes arrancaram o cérebro que permite a uma população sobreviver. As sanções, como o nome indica, fariam o resto do serviço, sem falar no rastro radioativo de bombas de urânio empobrecidos, na devastação ecológica etc. Já na guerra cosmopolita seguinte, inverteu-se o raciocínio estratégico, embora à procura do mesmo resultado: os bombardeios com grafite, por exemplo, visavam apagar o sistema elétrico da Sérvia, mas sem destruir sua infra-estrutura de base. Tanto num caso como no outro, comenta Paul Virilio, 'a eliminação que se busca é sempre a da vida, da vitalidade energética do adversário’. Em sua opinião, o modelo de contaminação viral e de irradiação atômica ou cibernética é patente, 'já não se trata tanto de fazer explodir uma estrutura, mas de neutralizar a infra-estrutura do inimigo, criando em seu meio e à sua volta a pane e o pânico pela interrupção vital de toda atividade coerente e coordenada' (Arantes, 2007, p. 61-62).

Sem possibilidade de circulação, sem meios de comunicação, abandonados à fome, à sede, às doenças, isolados uns dos outros, os indivíduos são reduzidos ao seu corpo e às necessidades impostas pelas exigências de sobrevivência. "Nem a vida nem a morte, mas a produção de uma sobrevivência modulável e virtualmente infinita constitui a tarefa decisiva do biopoder em nosso tempo", constatava Agamben (2008, p. 156) após ser conduzido pelos relatos dos sobreviventes de Auschwitz ao longo daquela zona cinzenta em que se produzia "em um corpo humano a separação absoluta entre o ser vivo e o ser que fala, entre a zoé e o bios, o não-homem e o homem: a sobrevivência" (Ibidem, p. 156). As guerras contemporâneas continuam a deslocar o limitar móvel da sobrevivência até encontrar o ponto de indiferenciação entre o ser vivo e o cadáver, a vida orgânica e os sinais que indicam a presença da morte, de forma lançar permanentemente a sombra ameaçadora da aniquilação sobre as existências que lutam por sobreviver, o que, como veremos a seguir, é a condição fundamental para a emergência da angústia.

Intervenções necropolíticas "neurocirúrgicas" desta natureza não são exclusividade 
das guerras e campanhas militares conduzidas por Estados visando à neutralização de populações inimigas. Transformada em uma commodity, a morte mobiliza uma rede de micro-governos, que mantém entre si e com o Estado relações múltiplas e polimorfas, cujos lucros são obtidos por meio de atividades direta ou indiretamente ligadas a uma economia necropolítica (Cf. Mbembe, 2012, p. 137). A exploração do poder da morte enriquece grupos armados locais, milícias, formações paramilitares, companhias privadas de segurança, forças estatais de repressão, indústrias bélicas, agências funerárias particulares...e, também, empresas neoliberais. Por mais contra-intuitivo que possa parecer em um primeiro momento, encontram-se nos manuais de gestão empresarial do trabalho algumas daquelas mesmas estratégicas necropolíticas de criação da pane e do pânico pela destruição sistemática das condições de vida dos trabalhadores. A incorporação dessas intervenções "neurocirúrgicas" faz com que o neoliberalismo utilize uma nova forma de dominação pela ameaça da precarização (Cf. Dejours, 2007, p. 52), "precarização que não concerne apenas ao emprego, mas também a toda a condição social e existencial" (Ibidem, p. 124). Fazer precarizar se torna, portanto, a máxima que orienta a ação da necropolítica e a partir da qual se pode alcançar dimensões menos evidentes do neoliberalismo autoritário.

\section{BREVES CONSIDERAÇÕES SOBRE O CONCEITO DE PRECARIADO}

É verdade que a experiência da precarização é vivida diferentemente de acordo com o gênero, a raça, ${ }^{1}$ a idade, a trajetória profissional do indivíduo, bem como depende do acesso ou não às políticas sociais, das condições

${ }^{1}$ As dimensões de gênero e racial são elementos centrais para análise dos processos de precarização e suas incidências diferenciais sobre a população brasileira. No entanto, lamentavelmente, não conseguiremos aprofundar neste artigo a discussão sobre tais dimensões, que serão tratadas em textos futuros. Aproveito para agradecer profundamente ao parecer que destacou a importância epistêmica da questão racial para a economia argumentativa deste trabalho. familiares e comunitárias que o rodeiam, dentre outros fatores. Contudo, esse tipo de ressalva, ainda que legítima, pode contribuir para fortalecer ainda mais a ideologia neoliberal que esvazia a precarização do seu caráter estrutural para transformá-la em um modo de ser referido exclusivamente ao indivíduo, o qual assume a inteira responsabilidade de superá-la por meio de esforços e estratégias igualmente individuais. Para não reproduzir essa ideologia, é essencial insistir em uma abordagem da precarização que leve em conta seus aspectos estruturais, sem, com isso, negligenciar as refrações singulares, histórica, geográfica e subjetivamente situadas, que incidem sobre o fenômeno.

No âmbito deste artigo, o processo de precarização é compreendido como parte constitutiva do modo de produção capitalista e da mercantilização da força de trabalho (Cf. Braga, 2012). Não era outra coisa que Marx ([1867] 2013) anunciava ao expor a relação do crescimento da ocupação industrial com a aparentemente paradoxal emergência de uma população de trabalhadores excedentes em relação à necessidades atuais do mercado, mas dos quais se poderia dispor virtualmente.

No caso do Brasil, a formação do precariado recua até os tempos iniciais da industrialização fordista do país (Cf. Braga, 2012) nos anos 1950, cujo crescimento se alimentou da imigração da força de trabalho precarizada oriunda do campo, das pequenas cidades e do Nordeste, principalmente. Esses trabalhadores participaram da primeira formação do precariado brasileiro, que, na esteira das considerações de Marx sobre a "superpolução relativa" (Marx, 2013, p. 718), Braga (2012, p. 16) define como uma parcela do proletariado na qual se reúnem: 1) os trabalhadores flutuantes, inseridos em relações de trabalho intermitentes e submetidos à altíssima rotatividade de ocupações em razão de serem semi - ou não qualificados; 2) a população latente, que se localiza nas fronteiras entre as ocupações formais e informais, como, por exemplo, os trabalhadores rurais que chegam à indústria; 3) a população 
estagnada, que "se reproduz de forma anormal" devido às sub-remunerações e às condições degradantes de trabalho e de existência. Em suma, precarizados são, portanto, os setores proletários mais explorados, "em permanente trânsito entre a possibilidade de exclusão socioeconômica e o aprofundamento da exploração econômica" (Ibidem, p. 17), espoliados dos direitos trabalhistas e sociais, e carentes de acesso à representação sindical ou que, na melhor das hipóteses, estão vinculados a sindicatos extremamente frágeis. Desse recorte, ressalva Braga (2012, p. 26), estão excluídos os setores mais qualificados do proletariado e, portanto, mais estáveis e melhor remunerados, e o lumpemproletariado, que não ocupa funções essenciais para a reprodução capitalista.

Enfatizar a pré-existência histórica do precariado e da precarização não significa dissolver a particularidade dessa camada social, enfraquecendo ou até implodindo sua efetividade heurística para expôr as novas contradições da estrutura capitalista neoliberal. ${ }^{2}$ Se o precariado não é nem novo, nem uma classe em si mesmo, suas configurações e dinâmicas se alteraram radicalmente sob efeito das mutações nos modos capitalistas de produção e suas consequências sobre o proletariado. Sem entrarmos nos detalhes desse diagnóstico, interessa-nos apenas destacar que, no Brasil, o aprofundamento da precarização pela adoção de medidas neoliberais a partir dos anos 1990 స్ empurrou gradativamente o precariado da in\ dústria e do trabalho formal para a esfera dos serviços, onde aderiu à informalidade, à subđ contratação ou às formas de terceirização, com $\stackrel{5}{\rightarrow}$ remunerações ainda mais baixas, maior des$\dot{\sim}$ proteção social e trabalhista, e intensa inseकే gurança existencial, potencializada, como ví$\Rightarrow$ nhamos dizendo, por medidas necropolíticas neoliberais de mercantilização territorial - que implica a gentrificação e processos de deslo-

${ }^{2}$ Essa é a principal crítica que Giovanni Alves endereça à definição de precariado construída por Ruy Braga: https:// blogdaboitempo.com.br/2013/07/22/o-que-e-o-precariado/. Para uma discussão mais aprofundada, recomendamos "Dimensões da Precarização do Trabalho", do mesmo Alves. camento forçado -, de destruição do sistema de assistência e saúde públicas, de redução ou desmantelamento dos benefícios sociais, previdenciários e laborais.

De lá pra cá, a precarização do trabalho apenas se agudizou, principalmente após a reforma trabalhista, ocorrida no governo Michel Temer, e a macabra associação do bolsonarismo com os efeitos da pandemia do COVID-19. Segundo dados da Pesquisa Nacional por Amostra de Domicílios (PNAD) Contínua, do Instituto Brasileiro de Geografia e Estatística (IBGE), referente ao trimestre encerrado em janeiro de 2021, a população ocupada no Brasil aumentou 2\% em relação ao trimestre anterior, dos quais $81 \%$ corresponde às ocupações informais (Cf. Carneiro, 2021). Com isso, o número de trabalhadores informais no país alcançou 34.148 milhões de brasileiros, 39,7\% do total da população ocupada (Carneiro, 2021). Já o trabalho intermitente, criado pelas reformas da CLT, corresponde atualmente à modalidade de contratação preferida das empresas brasileiras, submetendo milhares de pessoas a jornadas de trabalho indefinidas e, consequentemente, a ganhos variáveis, o que aprofunda o sentimento de insegurança existencial (Cf. Braga, 2021).

Face a tal conjuntura, não obstante as ressalvas de Braga, é possível supor uma ampliação dos precarizados no sentido de abarcar alguns setores pauperizados, particularmente aqueles que Marx (2013, p 719) alocava nas categorias dos que podem ser absorvidos pelo exército ativo. De fato, as modalidades intermitentes do trabalho, nas quais estão incluídas, como veremos, os trabalhadores de entregas por aplicativo, suspendem a distinção entre precariado e pauperizado como efeito da suspensão entre tempo de trabalho e tempo sem trabalho, como se estivéssemos diante da substancialização antinômica de um empregado-desempregado, cuja transição para um polo ou outro depende das decisões das empresas-aplicativo escondidas sob a máscara dos algoritmos. 


\section{FOME!}

“Fome!" é o grito de ordem do Movimento dos Entregadores Antifascistas, ${ }^{3}$ um movimento de abrangência nacional que reúne trabalhadores de entregas por aplicativo. Mais explicitamente do que nas reivindicações por melhorias salariais ou pelo reconhecimento de direitos que marcaram os movimentos operários nas últimas décadas, o gatilho para a atual mobilização dos trabalhadores de aplicativo vem das entranhas dos corpos famintos que se tornaram os principais responsáveis pela distribuição de alimentos durante a pandemia do novo Coronavírus. "O que me revoltava era trabalhar carregando comida nas costas de barriga vazia” (Lima apud Soprana, 2020, sp), sintetiza Paulo Roberto da Silva Lima, o "Galo", um dos principais mobilizadores do movimento de entregadores por aplicativo.

"Fome!". A esse primeiro grito, outros se fazem escutar: “sede!”, “dor!”, “frio”. Enquanto os lucros das empresa por aplicativo têm aumentado desde o início do isolamento social no Brasil, ${ }^{4}$ os trabalhadores de plataforma viram seus salários caírem progressivamente, dificultando ainda mais a conquista do mínimo necessário para sobreviver. De acordo com uma pesquisa (Cf. Abílio et al., 2020) coordenada pela Rede de Estudos e Monitoramento da Reforma Trabalhista (Remir Trabalho) e publicada em agosto de 2020, na qual foram entrevistados 252 trabalhadores de quatro distritos brasileiros, 60,3 por cento relataram queda na receita em comparação com o período pré-pandêmico, enquanto apenas 10,3\% declararam que estão ganhando mais dinheiro agora do que antes. Entre os entrevistados, 35,7\% relataram ganhar menos de R 260 por semana, o que representa duas vezes mais trabalhado-

3 https:/brasil.elpais.com/brasil/2020-06-28/galo-lanca-a-revolucao-dos-entregadores-de-aplicativo-essenciais-na-pandemia-invisiveis-na-vida-real.html

${ }^{4}$ A Rappi, uma das empresas-aplicativo de entrega, diz ter crescido cerca de $300 \%$ justamente no período inicial do isolamento imposto pela pandemia do novo Coronavírus (https://www.youtube.com/watch?v=fWnnD2V1IFE - último acesso em 10.07.2020). res nessa faixa de remuneração do que antes da crise disparada pelo COVID-19. Nesse cenário, mais trabalho não significa mais dinheiro, pois $56,4 \%$ dos entrevistados que trabalham mais de 9 horas por dia vêm sofrendo uma redução de 66,65\% em seus ganhos quando comparados com o período anterior à pandemia. Além dessa queda na receita, 62,3\% dos trabalhadores entrevistados afirmaram nunca ter recebido das empresas onde trabalham nenhum tipo de equipamento para se proteger da contaminação do vírus. Por isso, alguns deles decidiram pagar por suas próprias medidas de cuidado sanitário, como usar máscaras e luvas, levar desinfetante para as mãos e manter distância de segurança na entrega dos produtos.

"Fome!" porque o trabalhador perdeu seus laços de pertencimento a uma classe para ser reduzido ao seu corpo, sobre o qual pesa permanentemente a ameaça da aniquilação. "Fome!"

\section{A ECONOMIA NECROPOLÍTICA DA PLATAFORMIZAÇÃO DO TRABALHO}

Os trabalhadores por aplicativo estão na vanguarda da precarização neoliberal do trabalho. Desde que deixou a idealidade dos manuais de teoria econômica para ser testado em contextos nacionais tomados como laboratórios políticos a partir dos anos 1970, nos quais precisou assumir configurações híbridas e flexíveis (Cf. Ong, 2007; Andrade, 2019), o neoliberalismo se apresentou como uma racionalidade governamental com pretensão de integrar todas as esferas da existência humana segundo os princípios gerais da concorrência e do empreendedorismo (Cf. Dardot e Laval, 2009; Foucault, 2004).

Para tanto, não era suficiente estruturar a ação dos governos de modo a garantir a autonomia do mercado, ainda que às expensas do próprio Estado e, principalmente, dos seus aparelhos de segurança, de legislação e de justiça; fazia-se igualmente necessário governar as condutas dos indivíduos, no sentido que 
O termo "conduta”, apesar da sua natureza equívoca, talvez seja um daqueles que melhor permite atingir aquilo que há de específico nas relações de poder. A “conduta” é, ao mesmo tempo, o ato de "conduzir" os outros (segundo mecanismos de coerção mais ou menos estritos) e a maneira de se comportar num campo mais ou menos aberto de possibilidades. O exercício do poder consiste em "conduzir condutas” e em ordenar a probabilidade. O poder, no fundo, é menos da ordem do afrontamento entre dois adversários, ou do vínculo de um com relação ao outro, do que da ordem do "governo" (Foucault, 1995, p. 288).

Para governar é preciso administrar a liberdade, gerir a incondicionalidade do desejo por meio de um princípio de cálculo econômico que precisa ser internalizado pelos indivíduos. A governamentalidade neoliberal depende, portanto, de um

profundo trabalho de design psicológico, ou seja, de internalização de predisposições psicológicas visando a produção de um tipo de relação a si, aos outros e ao mundo guiada através da generalização de princípios empresariais de performance, de investimento, de rentabilidade, de posicionamento, para todos os meandros da vida. Desta forma, a empresa poderia nascer no coração e mente dos indivíduos (Safatle, 2021, p. 23).

Ou, mais explicitamente, os indivíduos mesmos deveriam se identificar com essa empresa. Nesse sentido, é preciso insistir que as dimensões autoritárias do neoliberalismo não se revelam apenas nas intervenções coercitivas do Estado e dos seus mecanismos, mas, também, nos dispositivos governamentais visando à produção do consenso e o engajamento dos indivíduos. Em uma palavra, ao se tratar do neoliberalismo autoritário não se pode perder de vista seus efeitos sobre a economia libidinal dos sujeitos, sobre a forma como esses in$>$ vestem determinadas relações e internalizam padrões ideais de conduta que pretendem normalizar as escolhas e decisões a partir do paradigma da empresa capitalista. Nesse sentido, Safatle insiste que

(...) a empresa não é apenas a figura de uma forma de racionalidade econômica. Ela é a expressão de uma forma de violência. A competição empresarial não é um jogo de críquete, mas um processo de relação fundado na ausência de solidariedade (...), no cinismo da competição que não é competição alguma (...), na exploração colonial dos desfavorecidos, na destruição ambiental e no objetivo monopolista final (2021, p. 25).

A violência impingida por meio dos processos de subjetivação neoliberais não se dissocia daquela efetivada pelo uso das forças de segurança e dos aparatos de justiça. Antes, entre uma e outra se estabelece uma série de alianças, sobreposições, compromissos. Por exemplo, quando a internalização de padrões de conduta e avaliação não é suficiente para colocar os sujeitos nos trilhos do mercado, a polícia é sempre o recurso suplementar à mão que intervém para salvar "os cidadãos de bem" das ameaças dos "vagabundos". Portanto, insistamos uma vez mais que o neoliberalismo autoritário precisa ser tomado como uma forma de racionalidade que se impõe - e busca conquistar adesão - pelo uso da violência de Estado associado ao recurso às violências de mercado, que incidem tanto sobre os corpos quanto sobre as subjetividades.

Voltando a esse último aspecto, o do design psicológico, é preciso levar em conta que, contemporaneamente, também participam da formação dos ideais empresariais com os quais os trabalhadores se identificam as chamadas empresas-aplicativo, representadas por Uber, Rappi, Ifood, James, Loggi, Amazon Mechanical Turk, PiniOn, Freelancer, 99Designs et caterva.

Apesar de relativamente recentes no mercado global, essas empresas fazem avançar para novos setores do mercado um conjunto de mudanças no mundo do trabalho que antecede a sua versão atual sob empuxo e impacto dos aplicativos: a terceirização, os serviços de venda direta e as formas estruturantes da exploração do trabalho nas áreas periféricas do capitalismo (Cf. Abílio, 2019a).

As pesquisas em sociologia do trabalho vêm cunhando diferentes conceitos para en- 
quadrar tais mudanças. ${ }^{5}$ A perspectiva assumida por este trabalho situa-se entre as teorias sobre a plataformização do trabalho (Cf. Casilli; Posada, 2019), entendida como um complexo processo global de renovação da forma de gestão, controle e expropriação do trabalho por meio de dispositivos digitais de gestão algorítmica de dados. Se optamos por utilizar a expressão dispositivos digitais, ao invés de simplesmente falarmos em aplicativos ou plataformas, é para enfatizar que a plataformização não se reduz a uma transformação de ordem tecnológica com vistas a renovar os meios de gestão do trabalho. Para além de um mero efeito de desenvolvimento técnico, a plataformização é mais propriamente um dispositivo, no sentido que Foucault constrói para este termo. Primeiramente, o dispositivo é uma rede mutável e heterogênea, “(...) comportando discursos, instituições, projetos arquiteturais, decisões regulamentares, leis, medidas administrativas, enunciados científicos, proposições filosóficas, morais, filantrópicas, em suma: tanto o dito quanto o não dito, eis os elementos do dispositivo" (Foucault, 2001b, p. 299). Nessa rede, eis o segundo aspecto destacado pelo filósofo francês, os fios que a tecem podem estabelecer entre si nós variáveis, criando, assim, novas conexões ou desfazendo as já existentes. Assim, a uma lei pode se conectar uma instituição e um discurso científico, por exemplo, ou a esse último podem se vincular projetos arquitetônicos e tecnologias variadas, "Em suma, entre esses elementos, discursivos ou não, existe como que um jogo, mudanças de posição, modificações de funções, que podem, eles também, ser muito diferentes "(Ibidem, p.299). Finalmente, o dispositivo é, a cada momento histórico, a resposta a um imperativo de urgência. Assim, "o dispositivo tem uma função estratégica dominante” (Ibidem, p.299). Não é possível compreendê-lo adequadamente, portanto, se o abstraímos das relações de

5 Tais como uberização, capitalismo de plataforma, trabalho sob demanda, entre outras. Não discutiremos neste texto as continuidades, as rupturas e os debates travados entre essas distintas abordagens teóricas. poder nos quais ele está inscrito. Contudo, a realização dessa função estratégica não é estática e unívoca, pois não só as urgências se transformam, mas o próprio dispositivo não é capaz de dominar todos os seus efeitos. Aqui, Foucault leva a meta-estabilidade inerente ao dispositivo para o campo das suas produções: "já que cada efeito, positivo e negativo, desejado ou não desejado, vem entrar em ressonância ou em contradição com os outros, e pede a uma retomada, a um reajustamento dos elementos heterogêneos que surgem aqui e ali” (Foucault, 2001b, p. 299). Assim, se por um lado há sempre um processo de "sobredeterminação funcional" do dispositivo, por outro lado isso exige um perpétuo "processo de realização estratégica", isto é, de recomposição do dispositivo de modo a capturar estrategicamente os efeitos residuais da sua própria ação.

Tomada como um dispositivo, a plataformização do trabalho envolve uma rede heterogênea e meta-estável de poderes e saberes - tecnologias, enunciados psicológico-morais, ações estatais, legislações, dados, algoritmos, inteligência artificial etc - associada estrategicamente à racionalidade neoliberal, ao autoritarismo e à financeirização do capitalismo.

Esse processo não se dá de maneira homogênea em todas as ramificações das atividades laborais. Nos próximos parágrafos, nossa análise se concentrará no que se designa como "plataformas que requerem o trabalhador em uma localização específica” (Ghroman, 2020, p. 113) ou "plataformas de trabalho territorial" (Braga, 2021), as quais incluem os chamados aplicativos de entrega e transporte. ${ }^{6}$ Apesar dessa circunscrição de escopo, algumas das características desse tipo de plataforma podem ser encontradas, com variações, em outros.

${ }^{6}$ Além destas, Grohman identifica "ii) plataformas de microtrabalho ou crowdwork (como Amazon Mechanical Turk, PiniOn, MicroWorkers), marcadas principalmente pelo trabalho de treinar dados4 para a chamada "inteligência artificial"5; iii) plataformas freelance, de clou- dwork ou macrotrabalho (como GetNinjas, WeDoLogos, Freelancer, iPres- tador, Fiver, 99Designs), que reúnem tarefas desde pintura e passeio com animais até design e programação" (2020, p. 113). 
No discurso da plataformização, ${ }^{7}$ não existe mais a figura do trabalhador coberto por direitos e garantias que limitavam minimamente sua relação com o capital; em seu lugar, surge o "parceiro" das empresas- aplicativo, ao mesmo tempo consumidor das tecnologias necessárias para a realização da sua atividade e prestador de serviços sob demanda para clientes anônimos. Entre parceiros e empresas a única relação que existe é a do livre contrato de adesão às cláusulas de cadastramento nos aplicativos. Após baixar o app, enviar os documentos solicitados e assinar o contrato - ainda estamos na gramática da plataformização -, o "parceiro" conquista a esperada autonomia laboral: sem chefe e hierarquias, sem jornada de trabalho pré-estabelecida, ele se supõe um empresário-de-si à espera de pedidos encaminhados por uma multidão de consumidores-avaliadores. Para receber estrelas, elogios e gorjetas - as quais vêm se tornando elemento essencial para a composição da renda mensal -, o trabalhador precisa desenvolver estratégias pessoais que garantam níveis ótimos de performance na concorrência com seus colegas plataformizados. Tais estratégias envolvem oferecer facilidades para os consumidores, como água, balas, carregadores de celular; estar atento aos avisos dos aplicativos sobre preço dinâmico, eventos e outras situações que podem fazer a demanda crescer em determinados momentos e em regiões específicas; interpretar ปี os sinais dos consumidores para saber orientar ำ entregar um alimento ainda fresco ao cliente;

${ }^{7}$ No que segue, baseamo-nos em um conjunto de trabalhos, particularmente em Abúlio (2020,2019a), Van Doorn (2017) e Grohman (2020). expor-se permanentemente a perigos decorrentes do comportamento de risco no trânsito ou daqueles derivados da própria execução da atividade por longos períodos de tempo. ${ }^{8}$ Os muitos obstáculos e problemas que surgem no cotidiano do trabalho são assumidos integralmente pelo trabalhador-parceiro, que se encarrega dos ônus e custos decorrentes de acidentes de trânsito, doenças ocupacionais, assaltos e furtos, pane nos veículos, obsolescência ou quebra do aparelho celular, problemas de conectividade com a internet etc.

Após a adesão ao contrato, a comunicação entre o plataformizado e a empresa -aplicativo se limita a notificações e a algumas mensagens automáticas. Afora essas situações pontuais, o contato com a empresa é experimentado pelo trabalhador como uma tarefa de Sísifo, sempre diferida por ligações que não se completam, emails que são respondidos automaticamente ou pela série incontável de mediadores terceirizados que trabalham para as empresas fornecendo explicações padronizadas para as interrogações que recebem dos trabalhadores.

As enormes limitações interpostas pelos aplicativos na comunicação com os seus "parceiros" constituem apenas uma das muitas estratégias de imunização (Cf. Van Doorn, 2017, p. 902) adotadas pelas empresas para se proteger de obrigações trabalhistas asseguradas pelas legislações, deslocando para cada trabalhador os ônus e custos derivados do exercício do seu trabalho. Outra dessas estratégias imunizatórias é a governança algorítmica dos trabalhadores por meio da qual as empresas conseguem um máximo de controle e gestão do trabalho, dos fluxos entre oferta e demanda, das informações e dados, com um mínimo de visibilidade, uma vez que as bonificações, a oscilação no valor dos pagamentos, as frequentes incoerências no sistema de distribuição de

${ }^{8} \mathrm{~A}$ respeito dos impactos da plataformização sobre a saúde física dos entregadores, recomendo aos leitores acompanharem os desdobramentos da pesquisa doutoral de Eduardo Rumenig, a quem agradeço pela sempre generosa partilha de reflexôes. 
pedidos e, inclusive, as arbitrariedades na definição de suspensões e cancelamentos de contas podem ser atribuídas à calculabilidade desinteressada dos softwares (Cf. Pasquale, 2015; Bucher, 2017).

No dia-a-dia das entregas e serviços plataformizados, o mal-estar dos trabalhadores revela a distância entre o ideal do empresário de si e as condições efetivas de trabalho. A queda progressiva dos valores pagos por quilômetro rodado enquanto se aumenta o tempo de espera por pedidos, as punições inexplicáveis, os riscos potencializados pelo contexto epidêmico, a necessidade de se cadastrar em mais de um aplicativo para garantir algum rendimento mensal - abaixo do suficiente -, as jornadas de trabalho que facilmente excedem dez horas diárias, os custos de manutenção dos equipamentos e instrumentos de trabalho, a sensação de que não se é ouvido nem reconhecido pela empresa, o sentimento de "estar batendo a cabeça" sozinho, os desgastes físicos sentidos no próprio corpo e no dos colegas, sem conseguir acesso fácil a banheiro, passando sede e fome, por esses e outros fatores, os plataformizados são mais propriamente autogerentes subordinados,

no sentido de que, submetido a um gerenciamento obscuro e cambiante que define/determina quanto ele pode ganhar e quanto tempo terá de trabalhar para tanto, o trabalhador estabelece estratégias de sobrevivência e adaptação, visando ao mesmo tempo decifrar, adequar-se à e beneficiar-se da forma como o trabalho é organizado, distribuído e remunerado. Essas estratégias também são previsíveis e integráveis à gestão. É preciso considerar ainda que o trabalhador não tem poder algum de interferência - nem mesmo de negociação - sobre as regras de distribuição e remuneração do trabalho (Abílio, 2020, p. 19-20).

Essas "estratégias de sobrevivência e adaptação”, no entanto, são vendidas pela "ideologia do Vale do Silício" (Schradie, 2017) como uma "ferramenta de liberdade" (Srnicek, 2016, p. 85), que contribui para engajamento de um número crescente de trabalhadores em atividades laborais plataformizadas. No Brasil, segundo dados da PNAD, até o início de 2019,
3,8 milhões de brasileiros utilizavam plataformas digitais como fonte de renda, transformando-as "no maior empregador do Brasil" (Estadão Conteúdo, 2019). Se levarmos em conta as pessoas que utilizam essas plataformas como fonte complementar, os índices sobem para 17 milhões de trabalhadores em 2019, a partir de pesquisa realizada pelo Instituto Locomotiva (Estadão Conteúdo, 2019). É provável que a histórica crise social resultante da epidemia do novo Coronavírus esteja impulsionando ainda mais o uso dos aplicativos como fonte prioritária ou complementar de renda familiar.

Nesta "multidão de trabalhadores disponíveis" (Abílio 2020, p. 112) reside outro elemento responsável pela gestão plataformizada da precarização: trata-se de suscitar no trabalhador a permanente sensação de superfluidade e obsolescência na medida em que sua força de trabalho é facilmente substituível por qualquer outra que, na superpolução relativa sempre crescente de plataformizados, aguarda seu lugar ao sol, ou melhor, seu lugar em algum ponto entre as milhares de conexões algorítmicas que levarão seu celular a tocar, finalmente! (Cf. Van Doorn, 2017).

A precarização do trabalho esteve na agenda do neoliberalismo desde seus primórdios. Ela é, a um só tempo, condição e efeito necessário da sobreposição de medidas legalmente asseguradas visando, por um lado, à promoção da competitividade internacional, da concorrência nacional de forma a estimular o fluxo de capital financeiro, da propagação da forma-empresa para todas as esferas de atividades humanas, incluindo o próprio Estado, e, por outro lado, à eliminação de direitos trabalhistas e sociais, principais responsáveis, segundo o credo neoliberal, pela crise global.

Para a massa de precarizados, existem, de um lado, as ofertas de trabalho precário, temporário e informal, associadas ao restritíssimo acesso ao que restou das políticas sociais emergenciais, e, do outro lado, a coerção estatal, na forma da polícia ou das instituições do sistema de justiça, responsável pela repressão 
aos movimentos que se interpõem à lógica neoliberal do mercado e pelo controle punitivista e carcerário da pobreza. Como temos enfatizado, o neoliberalismo autoritário se efetiva, então, como gestão da precariedade do corpo do trabalhador, ameaçando-o com espectro da obsolescência e da impossibilidade de sobreviver, e como poder repressor associado ao Estado.

Para encerrar esta sucinta introdução à necropolítica da plataformização, é essencial desvelar o viés racial e de gênero (Cf. Srnicek, 2017, p. 83; Van Doorn, 2017) que sustenta e simultaneamente é reforçado por esses novos dispositivos de gestão e subsunção do trabalho. Com efeito, em primeiro lugar, a plataformização dá visibilidade a um conjunto de elementos intrínsecos às formas de organização do trabalho periférico, sobretudo do trabalho feminino das mulheres negras periféricas (Cf. Abílio, 2019b); e, em segundo lugar, a massa dos trabalhadores de aplicativo no Brasil é composta por jovens negros periféricos, no caso dos apps de entrega, e por mulheres negras periféricas, quando se trata dos aplicativos que oferecem "serviços domésticos". Se, historicamente, a necropolítica incidiu de forma privilegiada no corpo negro capturado pelo sistema produtivo colonial na medida em que o excluía do campo do direito, da linguagem e do desejo, são esses mesmos corpos que continuam sendo precarizados como parte das estratégias necropolíticas de gestão dos trabaసิ

\section{PARA INTRODUZIR A GESTÃO} NEOLIBERAL AUTORITÁRIA DA ANGÚSTIA

Ao fazer avançar a destruição das condições de trabalho e de existência dos trabalhadores até se fazer ouvir o grito "fome!", a plataformização expõe as articulações viscerais entre neoliberalismo autoritário e necropolítica cujos efeitos sobre o corpo não são sem consequências subjetivas. Nesse ponto, a necropolítica se converte em uma necrogovernamentalidade (Cf. Franco, 2021), pois, para o poder, a morte não é apenas uma tecnologia de marcação, um instrumento de conservação da vida pela destruição das ameaças biológicas ou um fenômeno estatístico passível de regulação; ela é, também e principalmente, um dos elementos que delimitam as condições em que a vida é possível, na medida em que gerir as maneiras pelas quais se morre, como se morre, quem morre, do que se morre, o que acontece com o corpo após a morte, quais as formas de se prantear um morto, é gerir os riscos que pesam sobre a vida e, portanto, é administrar o quanto cada sujeito pode usufruir das possibilidades de ser livre, de escolher e desejar .

Sendo assim, poderíamos nos perguntar: qual tipo de subjetividade corresponde ao governo necropolítico da precarização do trabalho sob o neoliberalismo autoritário? Que disposições psicológicas o trabalhador precisa internalizar para que sua precariedade social e existencial possa ser mais eficazmente subsumida pelo capital? Abre-se, desta forma, outra dimensão pela qual se exerce o neoliberalismo autoritário: se, como vimos, a necropolítica, para fazer precarizar, incide sobre o corpo por meio da destruição sistemática das condições de vida e da repressão brutal da pobreza, a necrogovernamentalidade põe em marcha um processo de precarização subjetiva, fomentando formas de sofrimento psíquico que, a um só tempo, capturam e engajam os sujeitos na sua própria exploração pelo mercado.

À primeira vista, parece despropositado investigar a necrogovernamentalidade do neoliberalismo, uma vez que o discurso neoliberal, ao veicular demandas de performatividade, gozo, investimento, rentabilidade, estaria mais próximo a um dispositivo gestor da vida do que da morte e da precariedade.

Sem desconsiderar a face biopolítica do neoliberalismo, é preciso insistir que a plataformização deixa entrever que estas mesmas exigências psíquicas não são estranhas à dominação do trabalhador pela ameaça da precarização. 
A precarização, que resulta da progressiva destruição das condições laborais e de existência dos trabalhadores, tem como um dos seus efeitos subjetivos a angústia. Deste modo, nesta seção, pretendo introduzir algumas articulações entre a ameaça da precarização (Cf. Dejours, 2007) e a gestão neoliberal autoritária do trabalhador por meio da angústia.

É verdade que a angústia vem sendo preterida pelo discurso psiquiátrico, que, no Manual Diagnóstico e Estatístico de Transtornos Mentais (DSM), da Associação Norte-Americana de Psiquiatria, desde a sua terceira edição, tem preferido reunir sob a categoria "transtornos de ansiedade" um conjunto variado de sintomas, tais como o medo, o distúrbio de atenção, a falta de ar, a agorafobia, o mutismo seletivo, o transtorno de pânico, as fobias específicas e, inclusive, a categoria pouco evidente de transtornos de ansiedade não especificados. Ao tratar a angústia a partir de uma descrição sindrômica pretensamente neutra do ponto de vista axiológico, a racionalidade psiquiátrica do DSM recalca que os sofrimentos psíquicos têm estrutura relacional porquanto são expressão de conflitos entre exigências pulsionais e injunções normativas próprias das nossas instituições e organizações sociais (Cf. Safatle; Silva Júnior; Dunker, 2018, 2021). Em uma frase, o que se recalca são as condições sociais de emergência do sofrimento psíquico, os quais passam a ser atribuídos exclusivamente aos indivíduos.

Por isso, "hoje em dia são os psicanalistas que têm a responsabilidade da angústia" (Fingermann, 2016, p. 90), tanto porque a clínica psicanalítica não é sem angústia, quanto pelo fato de que cabe à psicanálise restituir a angústia as suas causas estruturais e estruturantes.

Desse ponto de vista, a emergência da angústia depende de conjunturas em que fracassam as formas subjetivas singulares sobre as quais cada um se apoia para interpretar e responder às exigências sociais que o convocam. Se, antes, esse sujeito podia gozar da suposta segurança a respeito de quem concebia ser, de quais eram as expectativas dos outros para com ele, de como deveria proceder diante de certos apelos, após o encontro com o traumático da experiência, isto é, com o advento de algo que rasga as telas interpretativas que enquadravam a maneira como encarava a vida, o sujeito "se vê questionado em sua existência, sem poder se reconhecer no passado nem imaginar o que será no futuro" (Berta, 2015, p. 97). Em suma, a angústia é o afeto do desamparo fundamental do sujeito, desamparo que Freud ([1926] 2014) compreendia como o resultado do sentimento de desintegração da possibilidade de significar de maneira total a experiência, inserindo-a na trama de conexões psíquicas que ligariam as excitações a fim de encontrar caminhos possíveis de satisfação. Tal impossibilidade de significar certos adventos da experiência coloca o sujeito diante de algo estranho, absolutamente Outro, uma alteridade opaca cujos limites, balizas, sentidos e significações são falhos e fazem falhar as que o sujeito mobiliza em sua defesa.

No entanto, como contra-intuitivamente afirmava Lacan, a impossibilidade de responder ao enigma de si e do Outro implica uma certeza: a "certeza de que isso quer dizer alguma coisa, sem que se saiba o que isso quer dizer" (Soller, 2012, p. 39), a certeza de que há uma significação que responde ao que não se sabe dizer o que é. Essa significação da significação vazia evoca a iminência de aparição do objeto com o qual o sujeito se identifica e que, enquanto ser-objeto, está à mercê do gozo do Outro. Em outras palavras, as situações de angústia colocam o sujeito face a face com o terror de responder na posição de objeto que o Outro é suposto demandar ou ser demandado para fazê-lo gozar. Para apresentar a angústia, Lacan ([1961-1962] 2003) se vale de uma alegoria:

Imaginem-se dentro de um recinto fechado, sozinho com uma louva-a-deus de três metros de altura. É a proporção correta para que eu tenha o tamanho do dito macho. Além do mais, estou vestido uma pele do tamanho do dito macho, que tem $1,75 \mathrm{~m}$, mais ou menos minha altura. Eu me miro, miro minha imagem assim fantasiada dentro do olho facetado 
da louva-a-deus fêmea. Será que a angústia é isso? É muito perto disso (Lacan, ([1961-1962] 2003, p. 243-244).

A alegoria só faz sentido se lembrarmos que a louva-a-deus fêmea, que é muito maior do que o macho da sua espécie, devora o parceiro após o acasalamento. Tal como essa pessoa que se descobre fantasiada de louva-a-deus macho ao ver seu reflexo no olho da fêmea, na angústia o sujeito se crê um objeto pronto para ser devorado pelo Outro. Para aqueles que chegam aos consultórios, a angústia é experimentada como uma sensação precisa de morte, um "morrer no gerúndio" (Fingermann, 2016, p. 94). A angústia, portanto, tem efeitos ontológicos, justamente porque ela diz respeito ao ser (Cf. Soller, 2012, p. 50), colocando em questão as construções imaginárias que constituíam as camadas sucessivas do $\mathrm{Eu}$ e a garantia que o sujeito encontrava sobre o assento da fantasia. Não por acaso, Soller se refere à angústia como uma "destituição subjetiva selvagem", isto é, "um momento em que o sujeito cessa de ser sujeito, em que ele se apreende como objeto e em que o desejo (como incógnita, como x, com todas essas ilusões que as incógnitas produzem sempre) fica suspenso" (Ibidem, p. 47).

Se a angústia é um sentimento universal, ela não deixa de ser sensível às modalidades dominantes de laço social, que se modificam segundo as épocas (Cf. Fingermann, 2016, p. 12). No caso que nos ocupa, o que mais aciసี ma denominamos a gestão da ameaça de pre-

De acordo com Fernandes et al. (2018, p.2345), de 2004 a 2013, o número de licenças concedidas devido a transtornos de ansieda- de "aumentaram de 615 para 12.818. No total, houve um aumento na ordem de $1.964 \%$ para este tipo de concessão". Em 2017, os dados analisados pela Organização Mundial da Saúde (OMS) revelaram que o Brasil é o país com o maior número de casos de transtorno de ansiedade no mundo, que incide em 9,3\% da população, três vezes mais que a média mundial (Estadão Conteúdo, 2019). Esses números corroboram a associação entre a agudização das transformações neoliberais no mundo do trabalho e o aumento da incidência de sofrimentos derivados da emergência da angústia.

Tal associação parece ser impensável sem que se leve em conta os impactos da neoliberalização sobre os laços laborais. A partir da análise que realizamos das plataformas digitais de entrega na seção 4, torna-se possível identificar o que nelas pode funcionar como ocasiões para a emergência da angústia. 1) o enfraquecimento e combate às formas de organização coletiva dos trabalhadores, levando à progressiva individualização do sofrimento e da responsabilidade do trabalhador. Associada à generalização do princípio da concorrência, não apenas os trabalhadores se vêem desvinculados de outros trabalhadores como esses são identificados a potenciais adversários na busca por melhores posições e mais reconhecimento (Cf. Dardot e Laval, 2009); 2) a intensificação da sensação de superfluidade, obsolescência e descartabilidade (Cf. Harvey, 2008, Van Doorn, 2017). 3) a impossibilidade de atribuir sentido ao cotidiano de trabalho, desde o fluxo de pedidos até a ocorrência de sanções arbitrárias, na medida em que as regras e formas de operacionalidade das empresas-aplicativo são frequentemente opacas. 4) a ausência de um Outro ao qual se pode endereçar a fala para perguntar, confrontar, solicitar, uma vez que ele foi substituído por algoritmos supostamente neutros que operam à despeito dos trabalhadores.

No entanto, à medida em que a gestão neoliberal autoritária das condições para a emergência da angústia produz a subordinação dos 
sujeitos, ela também estimula o engajamento do precariado como reação ao horror da ameaça sempre presente de destituição subjetiva. No caso dos precarizados-plataformizados, as estratégias de defesa passam pela multiplicação de atividades e comportamentos que vão da esquiva e fuga às situações que prenunciam a irrupção de angústia até as respostas estereotipadas por meio das quais se procura responder ao que o sujeito presume ser as exigências sociais requeridas para obtenção de amparo e segurança. Se a angústia é o afeto do desamparo decorrente da ruptura dos anteparos subjetivos que localizavam o sujeito em suas relações com o Outro, ao pressentir a irrupção do horror da angústia alguém pode buscar proteção por meio de reiteradas tentativas de reproduzir os ideais que supostamente lhe garantiriam o amor do Outro. Assim a exploração neoliberal do trabalho obtém a adesão dos trabalhadores às pressões por autovalorização permanente de si mesmos, principalmente por meio do cumprimento de metas, da superação de desafios e obstáculos mobilizados como parte das estratégias de gestão gamificada do trabalho (Cf. Scholtz, 2013; Rosemblat and Stark, 2016; Woodcock, 2019), do empenho pela maximização das suas performances na concorrência com seus companheiros, do consumo de mercadorias cuja propriedade contém a promessa de reconhecimento social (Cf. Pacheco Filho, 2015), da internalização de ideais de virilidade, tal como do caçador ou do guerreiro que enfrenta todos os perigos ainda que se colocando em risco de morte.

Estabelece-se, com isso, um circuito sem fim que transita entre a emergência da angústia e as respostas defensivas do sujeito, as quais, uma vez mobilizadas, confrontam-se novamente com a ameaça da precariedade. Por meio das intervenções necropolíticas de destruição sistemática dos recursos necessários à manutenção da vida e da montagem de dispositivos necrogovernamentais de gestão distributiva diferencial das condições de emergência da angustia, o neoliberalismo autoritário alcança, assim, a subordinação do precariado, coagido também policial e juridicamente, e o seu engajamento em formas de subjetividade que aprofundam a espoliação da sua força de trabalho.

Recebido para publicação em 30 d eabril de 2021 Aceito em 08 de novembro de 2021

\section{REFERÊNCIAS}

ABÍLIO, Ludmila. Plataformas digitais e uberização: Globalização de um Sul administrado? Contracampo 39, n. 1: 12-26, 2020. DOI - http://dx.doi.org/10.22409/ contracampo.v39i1.38579

ABÍLIO, Ludmila. Uberização: Do empreendedorismo para o autogerenciamento subordinado.. Psicoperspectivas, 18(3),41-51.2019a. Disponível em: DOI https://dx.doi.org/10.5027/ psicoperspectivas-vol18-issue3-fulltext-1674. Acesso em: 10.08.2021.

ABÍLIO, Ludmila. Uberização e viração: Mulheres periféricas no centro da acumulação capitalista. Revista Margem Esquerda. v. 31, p. 54-61. 2019b.

ABÍLIO, Ludmila et al. Condições de trabalho em empresas de plataforma digital: os entregadores por aplicativo durante a Covid-19. São Paulo: REMIR, 2020.

AGAMBEN, G. O que resta de Auschwitz: o arquivo e a testemunha. Tradução de Salvino J. Assmann. São Paulo: Boitempo, 2008. (Estado de Sítio).

AGAMBEN, G. Homo Sacer: o poder soberano e a vida nua I. 2. ed. Tradução de Henrique Burigo. Belo Horizonte: UFMG, 2002

ANDRADE, Daniel P."O que é o neoliberalismo? A renovação do debate nas ciências sociais.” Sociedade e Estado. 34: 211-239, 2019. Disponível em: DOI 10.1590/ s0102-6992-201934010009. Acesso em: 20.08. 2021.

ARANTES, Paulo. Extinção. São Paulo: Boitempo, 2007.

BERTA, Sandra L. Localização da urgência subjetiva em psicanálise. A peste. São Paulo, v. 7, n. 1, p. 95-105, jan./ jun. 2015.

BRAGA, Rui. A política do precariado. São Paulo: Boitempo, 2012.

BRAGA, Rui. As faces ignoradas do uberismo. [Produzido por] OutrasPalavras. [S.l.:s.n.], 15 de abril de 2021. 1 vídeo (22min42seg). Disponível em: https://www.youtube. $\mathrm{com} /$ watch? $\mathrm{v}=\mathrm{x} 4 \mathrm{moDtxDl} 4 \mathrm{I} \& \mathrm{t}=332 \mathrm{~s}$. Ultimo acesso em 24.04.2021.

BUCHER, T. "The Algorithmic Imaginary: exploring the ordinary affects of Facebook algorithms". Information, Communication \& Society, v. 20, n. 1: 30-44, 2017.

CARNEIRO, Lucianne. IBGE: informalidade responde por maior parte do aumento da população ocupada. Valor, Rio de Janeiro, 31 de março de 2021. Disponível em: https://valor.globo.com/brasil/noticia/2021/03/31/ibgeinformalidade-responde-por-maior-parte-do-aumento-dapopulacao-ocupada.ghtml. Último acesso em 24.04.2021.

CASILLI, A.; POSADA, J. "The Platformization of Labor and Society". In: GRAHAM, M.; DUTTON, W. (org.). Society and the Internet. Oxford: OUP, 2019. p. 293-306. 
DARDOT, Pierre; LAVAL, Christian. La nouvelle raison du monde. Essai sur la société néolibérale. Paris: La Découverte, 2009.

DEJOURS, Christophe. A banalização da injustiça social. Translated by Luiz Alberto Monjardim. Rio de Janeiro: Editora da FGV, 2007.

ESPOSITO, Roberto. Bíos: biopolitica e filosofia. Turin: Einaudi, 2004.

ESTADÃO CONTEÚDO. Brasil é o país mais ansioso do mundo, segundo a OMS. Exame. 05 de junho de 2019. Disponível em: https://exame.com/ciencia/brasil-e-o-paismais-ansioso-do-mundo-segundo-a-oms/. Acesso em 24.04.2021.

ESTADÃO CONTEÚDO. Apps como Uber e Ifood se tornam 'maior empregador' do Brasil. Exame, 28 de abril de 2019. Disponível em: https://exame.com/economia/ apps-como-uber-e-ifood-sao-fonte-de-renda-de-quase-4milhoes-de-pessoas/. Acesso em 24.04.2021.

FERNANDES, Márcia Astrês et al. Prevalência dos transtornos de ansiedade como causa de afastamento de trabalhadores. Rev. Bras. Enferm., Brasília, v. 71, supl. 5, p. 2213-2220, 2018.Disponível em: <http://www. scielo.br/scielo.php?script=sci arttext\&pid=S0034$71672018001102213 \& \operatorname{lng}=\mathrm{en} \& \mathrm{nrm}=\mathrm{iso}>$. Acesso em: 25.04.2021

FINGERMANN, Dominique. Pânico e fobia: enlace e desenlace da angústia. Comunicação de uma pesquisa em curso. Stylus (Rio I.), Rio de Janeiro, n. 32, p. 89-98, jun. 2016. Disponível em <http://pepsic.bvsalud.org/scielo. php?script = sci arttext\&pid=S1676-157X2016000100009 \&lng $=p t \& n r m=i$ iso $>$. Acesso em: 25.04. 2021.

FOUCAULT, Michel. O sujeito e o poder. In: DREYFUS, H.; RABINOW, P. Michel Foucault. Uma trajetória filosófica: para além do estruturalismo e da hermenêutica. Rio de Janeiro: Forense Universitária, 1995.

FOUCAULT, Michel. É preciso defender a sociedade: curso no Collège de France (1975-1976). São Paulo: Martins Fontes, 1997.

FOUCAULT, Michel. Dits et écrits I: 1954-1975. Paris: Gallimard, 2001a.

FOUCAULT, Michel. Dits et écrits II: 1976-1988. Paris: Gallimard, 2001b.

FOUCAULT, Michel. Naissance de la biopolitique. Paris: Seuil, 2004

FRANCO, Fábio Luís Ferreira Nobrega. Governar os mortos: Necropolíticas, desaparecimento e subjetividade. São Paulo: Ubu Editora, 2021.

స్ FREUD, S. Inibição, sintoma e angústia. 1a. edição [1926] ㄱ In: Inibição, sintoma e angústia, O futuro de uma ilusão e ғ outros textos (1926 - 1929). Traduzido por Paulo César de ○ Souza. São Paulo: Companhia das Letras, 2014.

フิ GROHMAN, R. Plataformização do trabalho: entre datificação, financeirização e racionalidade neoliberal. เి Revista Eptic. v. 22 n. 1, jan/abr. 2020. p. 106-122.

־ HARVEY, D. O neoliberalismo: história e implicações. São ?. Paulo: Loyola, 2008.

ले

LACAN, J. La troisième. 1a. edição [1974]. In: Opção Lacaniana n. 62. São Paulo: Escuta, 2001.

อ

LACAN, J. A identificação: seminário 1961-1962. 1a. edição [1962-1963]. Recife: Centro de Estudos Freudianos do Recife, 2003
MARX, K. O Capital: crítica da economia política. 1.a edição [1867]. São Paulo: Boitempo, 2013.

MBEMBE, A. Necropolítica, una revisión crítica. In: BARRIOS, J. L.; MAC GREGOR, H. C.; EXPÓSITO, M. et ali. Estética y violencia: necropolítica, militarización y vidas lloradas. México: Museo Universitario Arte Contemporáneo/Universidad Nacional Autónoma de México, 2012, p. 131-139.

MBEMBE, A. Necropolitics. Public Culture 15(1):11-40. [s.l.]: Duke University Press, 2003.

ONG, A. Neoliberalism as a mobile technology. Transactions of the Institute of British Geographers, v. 32: 3-8, 2007.

PACHECO FILHO, R. Compra um Mercedes Benz prá mim? Psicologia Revista, 24(1), 15-44, 2015. Disponível em: https://revistas.pucsp.br/index.php/psicorevista/ article/view/24227 Último acesso em 24.04.2021.

PASQUALE, F. The Black Box Society. Harvard: HUP, 2015.

ROSENBLAT, Alex; STARK, L. Algorithmic Labor and Information Asymmetries: A Case Study of Uber's Drivers. International Journal of Communication, v. 10, n. X: 37583784, 2016.

SAFATLE, V. A economia é a continuação da psicologia por outros meios: sofrimento psíquico e o neoliberalismo como economia moral. In: SAFATLE, V.; SILVA JÚNIOR, N. da.;DUNKER, C. (org.). Neoliberalismo como gestão do sofrimento psíquico. Belo Horizonte: Autêntica, 2021. p. 11-38.

SAFATLE, V.; SILVA JÚNIOR, N. da.; DUNKER, C. Patologias do social: arqueologias do sofrimento psíquico Belo Horizonte: Autêntica., 2018.

SAFATLE, V.; SILVA JÚNIOR, N. da.; DUNKER, C. (org.). Neoliberalismo como gestão do sofrimento psíquico. Belo Horizonte: Autêntica, 2021.

SCHOLTZ, T. (ed.) Digital labor: The internet as playground and factory. London: Routledge, 2013.

SCHRADIE, J. Ideologia do Vale do Silício e Desigualdades de Classe. Parágrafo, v. 5, n. 1: 86-99, 2017.

SOLLER, Colete. Declinações da angústia. São Paulo: Escuta, 2012.

SOPRANA, Paula. Acreditaram na mentira do empreendedorismo, diz líder dos Entregadores Antifascistas. Folha de São Paulo, São Paulo, 09 de julho de 2020. Disponível em: https://www1.folha. uol.com.br/mercado/2020/07/acreditaram-na-mentirado-empreendedorismo-diz-lider-do-entregadoresantifascistas.shtml?origin $=$ folha. Ultimo acesso em 24.04.2021.

SRNICEK, N. Platform Capitalism. London: Polity, 2016.

VAN DOORN, N. Platform labor: On the gendered and racialized exploitation of low-income service work in the 'on-demand' economy. Information, Communication \& Society, 20(6), 898-914, 2017. Disponível em: https:// doi.org/10.1080/1369118X.2017.1294194 Último acesso: 10.12. 2020

WOODCOCK, J. Marx at the Arcade: Consoles, Controllers, and Class Struggle. Chicago: Haymarket Books, 2019. 
MAKING IT PRECARIOUS: authoritarian neoliberalism and necrogovernmentality

Fábio Luís Franco

This article analyses the articulations between necropolitics and neoliberal labor management in Brazil. It is intended to argue that authoritarian neoliberalism operates both coercively, using the apparatus of security and justice, and through the management of psychological suffering and the processes of subjectivation. For this, it starts from the understanding that neoliberal necropolitics involves, also, interventions aiming to make precarization, that is, to produce suffering in the bodies through the administration of deadly conditions, as becomes explicit with the neoliberal platformization of work in Brazil. Finally, the article introduces some considerations about the impacts of this neoliberal necropolitical management of precariousness on the forms of subjectivation of workers, shedding light on neoliberal necrogovernmentality as management of the conditions of emergence of anguish.

KEYwORD: Necropolitics. Neoliberalism. Platform. Work. Anguish.

\section{FAIRE PRECARISER : néolibéralisme autoritaire et nécrogouvernementalité}

Fábio Luís Franco

Cet article analyse les articulations entre la nécropolitique et la gestion néolibérale du travail au Brésil. Il vise à soutenir que le néolibéralisme autoritaire opère à la fois de manière coercitive, en utilisant l'appareil de sécurité et de justice, et par la gestion de la souffrance psychologique et les processus de subjectivation. Pour cela, il part de la compréhension que la nécropolitique néolibérale implique également des interventions visant à précariser, c'est-à-dire à produire de la souffrance dans les corps à travers l'administration de conditions mortelles, comme cela devient explicite avec la plateformisation néolibérale du travail au Brésil. Enfin, l'article introduit quelques considérations sur les impacts de cette gestion nécropolitique néolibérale de la précarité sur les formes de subjectivation des travailleurs, mettant en lumière la nécrogouvernamentalité néolibérale comme gestion des conditions d'émergence de l'angoisse.

Mots CLÉs: Nécropolitique. Néolibéralisme. Plateforme. Travail. Angoisse.

Fábio Luís Franco - Doutor em Filosofia pela Universidade de São Paulo e psicanalista membro do Fórum do Campo Lacaniano de São Paulo. Pesquisador de pós-doutorado vinculado ao International Research Group on Authoritarianism and Counter-Strategies (IRGAC), do Rosa Luxemburg-Stiftung, e ao Instituto de Psicologia da USP. Visiting Scholar na cátedra de "Sociology of the Future of Work" na Einstein Center Digital Future e na Humboldt-University em Berlim. Pesquisador-membro do Laboratório de Teoria Social, Filosofia e Psicanálise (LATESFIP-USP). Publicações recentes: Brasil: um laboratório do desaparecimento. In: VANNUCHI, C.; VILALTA, L. P. (org). Vala de Perus: um crime não encerrado da ditadura militar. Salto, SP: Fox Tablet, Instituto Vladimir Herzog, 2021. p. 215 -227; FRANCO, F. et al. O sujeito e a ordem do mercado: gênese teórica do neoliberalismo. In: SAFATLE, V.; SILVA JÚNIOR, N. da.; DUNKER, C. (org.). Neoliberalismo como gestão do sofrimento psíquico. Belo Horizonte: Autêntica, 2021. 
